\title{
Expression of 53BP1 as a cisplatin-resistant marker in patients with lung adenocarcinomas
}

\author{
TAN-CHEN LAI ${ }^{1,2}$, KUAN-CHIH CHOW $^{3}$, TZE-YI LIN ${ }^{4}$, I-PING CHIANG ${ }^{4}$, \\ HSIN-YUAN FANG ${ }^{5}$, CHIH-YI CHEN ${ }^{5}$ and SHU-PENG HO ${ }^{2}$ \\ ${ }^{1}$ Department of Medical Laboratory Science and Biotechnology, Central Taiwan University of Science and \\ Technology; ${ }^{2}$ Department of Veterinary Medicine and ${ }^{3}$ Graduate Institute of Biomedical Sciences, \\ National Chung Hsing University; Departments of ${ }^{4}$ Pathology and ${ }^{5}$ Surgery, China Medical \\ University Hospital, China Medical University, Taichung, Taiwan, R.O.C.
}

Received January 29, 2010; Accepted April 12, 2010

DOI: 10.3892/or_00000862

\begin{abstract}
DNA repair is one of the major causes of spontaneous drug and radiation resistance in patients with lung adenocarcinomas (LADC). 53BP1 is a mediator that relays signals from DNA damage sensors and activates various effectors for the DNA repair and cell survival. In this study we investigated the clinical and biological significance of 53BP1. Expression of 53BP1 was detected by immunoblotting and immunohistochemistry. Our data showed that 53BP1 was detected in $166(75.8 \%)$ of 219 LADC patients. Expression of 53BP1 correlated with tumor stage, cigarette smoking, lymphovascular invasion and poor clinical outcome. In vitro, increased 53BP1 expression elevated drug resistance, and silencing of 53BP1 expression reduced cisplatin resistance.
\end{abstract}

Correspondence to: Dr Kuan-Chih Chow, Graduate Institute of Biomedical Sciences, National Chung Hsing University, Taichung, Taiwan, R.O.C.

E-mail:kcchow@dragon.nchu.edu.tw

Dr Shu-Peng Ho, Department of Veterinary Medicine, National Chung Hsing University, Taichung, Taiwan, R.O.C.

E-mail: spho@dragon.nchu.edu.tw

Abbreviations: AIF, apoptosis inducing factor; ATM, ataxiatelangiectctasia mutated; ATR, ATM and Rad 3-related; CIP, calf intestinal alkaline phosphatase; ERCC1, excision repair crosscomplementation group 1; 53BP1, p53 binding protein 1; HGF, hepatocyte growth factor; hHR23B, human homolog of yeast Rad23 protein B; LADC, lung adenocarcinomas; MRN, Mre11/Rad50/ NBS1; NER, nucleotide excision repair; NHEJ, non-homologous endjoining; NTLT, non-tumor lung tissues; RPA, replication protein A; RT-PCR, reverse transcription-polymerase chain reaction; SCLC, small cell lung cancer; TFIIH, RNA polymerase II basal transcription factor b; TFB5, transcription factor B5; XPC, Xeroderma pigmentosum complementation group $\mathrm{C}$

Key words: 53BP1, DNA repair, cisplatin resistance, lung adenocarcinoma, cigarette smoking
Our results suggest that 53BP1 expression plays an important role in cisplatin resistance and predicts the prognosis for LADC.

\section{Introduction}

Lung cancer is the leading cause of cancer death worldwide. Among the four pathological subtypes, small cell lung cancer (SCLC), lung adenocarcinoma (LADC), squamous cell carcinoma and large cell carcinoma (1), LADC is featured by the rapid growth and high metastatic potential. Most importantly, the disease is resistant to therapy using anticancer drugs or radiation, the clinical performance that is reflecting in the poor prognosis $(2,3)$. Drug and radiation resistance is correlated with cell cycle progression and capability of DNA repair (4). Both mechanisms are regulated by p53, a genome guardian, which induces cell cycle arrest whilst cells encounter genomic damage to allow DNA repair or induce apoptosis (5-7). Expression of p53 is thus important for determining drug and radiation resistance as well poor prognosis $(8,9)$.

Using a yeast two-hybrid method, Iwabuchi et al identified two proteins, p53 binding protein 1 (53BP1) and 53BP2, which could interact with DNA binding domain of wild-type, but not mutant p53 (10). Both proteins are required for the induction of p53-dependent transcription activation (11). In addition, the $220-\mathrm{kDa} 53 \mathrm{BP} 1$, in particular, acts as a mediator to relay signals from DNA damage sensors, ataxiatelangiectasia mutated (ATM) and ATM and Rad 3-related (ATR) kinases, to activate the various effectors, which are required for the DNA repair and cell survival (11-14). Therefore, it is reasonable to ask whether 53BP1 expression has any prognostic significance in patients with LADC.

In this study, we used an immunohistochemical method to determine 53BP1 expression in surgical specimens from patients with the LADC. Expression of 53BP1 was confirmed by immunoblotting. Correlation between clinicopathological parameters and 53BP1 expression and the prognostic significance of 53BP1 expression in patients with LADC were evaluated. The effect of 53BP1 expression on cisplatin resistance was measured in vitro. 


\section{Materials and methods}

Non-small cell lung cancer (NSCLC) cell lines. One breast cancer (MCF-7) and seven NSCLC (H23, H226, H838, H1437, H2009, H2087 and A549) cell lines were used for the in vitro evaluation of gene expression. H23, H838, H1437, $\mathrm{H} 2009$, H2087 and A549 are LADC cells, and H226 is an epithelial type cell $(2,3)$. Cells were grown at $37^{\circ} \mathrm{C}$ in a monolayer in RPMI-1640 supplemented with $10 \%$ fetal calf serum (FCS), $100 \mathrm{IU} / \mathrm{ml}$ penicillin and $100 \mu \mathrm{g} / \mathrm{ml}$ streptomycin.

Patients and tissue specimens. From January 2001 to December 2002, tissue specimens were collected from 219 patients with newly diagnosed LADC. Samples from all patients, for whom at least one follow-up examination or death was documented, were pathologically confirmed LADC. The stage of the disease was classified according to the new international staging system for lung cancer (15). The Medical Ethics Committee approved the protocol, and written informed consent was obtained from every patient before surgery. All patients had undergone surgical resection and radical N2 lymph node dissection. Tumor size, lymph node number, differentiation, vascular invasion and mitotic number were also evaluated. Patients with lymph node involvement or loco-regional recurrence received irradiation at the afflicted areas. Those with distant metastasis were treated with chemotherapy. After treatment, patients were routinely followed every 3-6 months in the outpatient department. Results from blood examination, biochemical studies, chest radiography, abdominal sonography, whole body bone scan and computerized tomography scans of chest that indicated any evidence of disease were interpreted as tumor recurrence and metastasis. The average age of male patients $(n=153)$ was $58.9 \pm 4.58$ years and that of female patients $(n=66)$ was $54.8 \pm 3.62$ years $(\mathrm{p}<0.05)$. Immunohistochemical staining was carried out using a single-blind procedure.

RNA extraction and reverse transcription-polymerase chain reaction $(R T-P C R)$. Total RNA was isolated from frozen tissues by a SNAP RNA column (Invitrogen, San Diego, CA). After measuring RNA yield, cDNA primed with oligo random primers was synthesized by AMV reverse transcriptase. Following total RNA extraction and synthesis of the first-strand cDNA, an aliquot of cDNA was subjected to 35 cycles of PCR to determine the integrity of B-actin mRNA $(2,3)$. The cDNA used in the following RT-PCR was adjusted according to the quality and quantity of $B$-actin mRNA. The primer sequences were selected by Primer3 (http://frodo. wi.mit.edu/primer3). The primers for $53 \mathrm{BP} 1$ are: $53 \mathrm{BP} 1 \mathrm{~s}$, 5'-TGGGAATGTCAGTGGAATCTGCTC-3' (sense primer, nts 535-558, AF078776); and 53BP1a, 5'-GGTGTTGAGGC TTGTGGTGATA-3' (antisense primer, nts 1477-1456). The primers for $\beta$-actin are: 5'-AGAGCTACGAGCTGCCTG AC-3' (sense primer, nts 797-816, NM_001101.3) and 5'-CA CCTTCACCGTTCCAGTTT-3' (antisense primer, nts 13751356). The amplified DNA fragment is 943 base-pair (bp) for 53BP1 and 579 bp for $\beta$-actin.

Cytotoxicity assay. Cells were seeded at 5000 cells/well $18 \mathrm{~h}$ prior to challenge with various doses of cisplatin. The control group was treated with RPMI-1640. Following cell challenge for $48 \mathrm{~h}, 10 \mu \mathrm{l}$ of WST-1 (BioVision, Mountain View, CA) was added and continued incubation for $2 \mathrm{~h}$. Percent survival of cells was quantified by comparing the number of viable cells in the treatment group with that in the control group. All procedures were performed in triplicate. This assay measures both replicating and static cells $(2,3)$.

Colony forming assay. Cells were seeded at 100, 500, 2000 and 10000 cells $/ 6 \mathrm{~cm}$ culture plate. The cells were treated with various concentrations of cisplatin for $12 \mathrm{~h}$, and then the drug was washed off with PBS. Following drug challenge, the cells were incubated at $37^{\circ} \mathrm{C}$ for 10 days until cell colony ( $\geq 50$ cells/colony) appeared (16). Percent survival of cells was quantified by comparing the number of viable cell colonies in the treatment group with that in the control group. All procedures were performed in triplicate. This assay measures only replicating cells.

Preparation of mouse antibodies. DNA sequence corresponding to N-terminal fragment (amino acid residues 119422) of human 53BP1 (h53BP1-N) was amplified by primer sequences containing EcoRI (sense) and HindIII (antisense) restriction sites respectively. The primer sequences were 53BP1s: 5'-TCCGAATTCGTTCTGGGAATGTCAGTGG-3' (EcoRI site is underlined) and 53BP1a: 5'-GCAAGCTTG GCTCAGTGTTGAGGCTTGTGGTGATA-3' (HindIII site is underlined).

The DNA fragment of h53BP1 was cloned into an expression vector pET-32b+ (Promega KK, Tokyo, Japan). Bacterial colony containing $\mathrm{pET} 32^{+}-\mathrm{h} 53 \mathrm{BP} 1-\mathrm{N}$ was selected and induced by isopropyl- $\beta-D$-thiogalactopyranoside (IPTG) to massproduce h53BP1-N. The recombinant protein was purified by a nickel-affinity column. Affinity-purified h53BP1-N was used to immunize BALB/c mice, and sensitivity of antiserum $\left(\mathrm{OD}_{405}>0.3\right.$ at 1:6000 dilutions) was measured by enzymelinked immunosorbent assay (ELISA). Specificity of antibodies was determined by the appearance of a 220-kDa band in immunoblotting of lung cancer cell extract (10). Monoclonal antibodies were produced by a hybridoma technique, and 53BP1-specific antibodies were screened by the abovementioned methods.

Immunoprecipitation, gel electrophoresis and protein analysis by MALDI-TOF. Total cell lysate was prepared by mixing $5 \times 10^{7}$ cells $/ 100 \mu 1$ phosphate-buffered saline with equal volume of $2 \mathrm{X} \mathrm{NP}-40$ lysis buffer [ $40 \mathrm{mM}$ Tris-HCl, pH 7.6, 2 mM EDTA, $300 \mathrm{mM} \mathrm{NaCl}, 2 \% \mathrm{NP}-40$ and $2 \mathrm{mM}$ phenylmethylsulfonylfluoride (PMSF)]. Protein G sepharose ${ }^{\mathrm{TM}}$ (Amersham Biosciences AB, Uppsala, Sweden) was prewashed before mixing with $500 \mu \mathrm{g}$ of total cell lysate. The reaction mixture was incubated at $4^{\circ} \mathrm{C}$ for $60 \mathrm{~min}$, and then centrifuged at $800 \mathrm{x}$ g for $1 \mathrm{~min}$. The supernatant was reacted with $5 \mu \mathrm{g}$ of purified monoclonal antibodies and $20 \mu \mathrm{l}$ of fresh protein $\mathrm{G}$ sepharose at $4^{\circ} \mathrm{C}$ for $18 \mathrm{~h}$. The reaction mixture was centrifuged at $800 \mathrm{x}$ g for $1 \mathrm{~min}$. Following removal of the supernatant, the precipitate was washed with $1 \mathrm{X}$ PBS, and dissolved in loading buffer (50 mM Tris, $\mathrm{pH} 6.8,150 \mathrm{mM}$ $\mathrm{NaCl}, 1 \mathrm{mM}$ disodium EDTA, $1 \mathrm{mM}$ PMSF, $10 \%$ glycerol, $5 \%$ ß-mercaptoethanol, $0.01 \%$ bromophenol blue and $1 \%$ 
SDS). Eletrophoresis was carried out in two $10 \%$ polyacrylamide gels with $4.5 \%$ stacking. One gel was processed for immunoblotting, and the other gel was stained with Coomassie blue $(2,3)$. Protein on the Coomassie-stained gel, which corresponded to the immunoblotting-positive band, was extracted from the gel for identification by MALDI-TOF on a Voyager-DE $^{\mathrm{TM}}$ pro biospectrometry workstation (Applied Biosystems, Milpitas, CA, USA). Fragments of peptide fingerprints were matched with those on the SwissProt database by MS-fit (ProteinProspector 4.0.5., The Regents of the University of California).

Immunoblot analysis. After gel electrophoresis, proteins were transferred to a nitrocellulose membrane for immunoblotting $(2,3,16)$. Nitrocellulose membrane was probed with specific antibodies. The signal was amplified by biotinlabeled goat anti-mouse IgG and peroxidase-conjugated streptavidin. The protein was visualized by exposing the membrane to an X-Omat film (Eastman Kodak, Rochester, NY) with chemiluminescent reagent (NEN, Boston, MA) $(2,3)$.

Immunocytochemistry and immunohistochemistry. Both immunocytochemical and immunohistological stainings were performed by an immunoperoxidase method using labeled streptavidin-biotin complex (Dako, LSAB2 System, Carpenteria, CA) (2,3). For confocal immunofluorescence microscopy, the second antibodies contained fluorescence proteins. Briefly, following removal of paraffin with xylene and absolute alcohol, antigen was retrieved by treating samples in boiling water for $10 \mathrm{~min}$. Endogenous myeloperoxidase was inactivated with $3 \% \mathrm{H}_{2} \mathrm{O}_{2}$ and $0.1 \%$ sodium azide at room temperature (RT) for $15 \mathrm{~min}$. After incubation with monoclonal antibodies (1:100 dilutions) specific to 53BP1 at RT for $2 \mathrm{~h}$, specimens were treated with biotin-conjugated goat anti-mouse immunoglobulin, and then peroxidase-conjugated streptavidin. Chromogenic development was in 3-amino-9ethylcarbazole (AEC). The slides were counterstained with $50 \%$ hematoxylin in tap water at RT for $45 \mathrm{sec}$ and the blue color was enhanced in running water for $20 \mathrm{~min}$. The crimson precipitates were identified as positive staining. A section of gelatin-embedded H23 LADC cells was used as a positive control and a non-tumor lung tissue (NTLT) served as a negative control in each run of immunostaining.

Slide evaluation. In each pathological section, NTLT served as internal negative control. Slides were evaluated by two pathologists blinded to the clinicopathological knowledge. The ImmunoReactive Scoring system was adapted for this study (17). Briefly, a specimen was considered having a strong signal when $>50 \%$ of cancer cells were positively stained; intermediate, if $25-50 \%$ of the cells stained positive; weak, if $<25 \%$ or $>10 \%$ of the cells were positively stained; and negative, if $<10 \%$ of the cells were positively stained. Cases with strong and intermediate 53BP1 signals were classified as $53 \mathrm{BP} 1^{+}$, and those with weak or negative 53BP1 signals were classified as $53 \mathrm{BP} 1^{-}$.

Statistical analysis. The relationship between 53BP1 expression and clinicopathological parameters was analyzed by $\chi^{2}$ test. The $\chi^{2}$ test for trend was used when corresponding

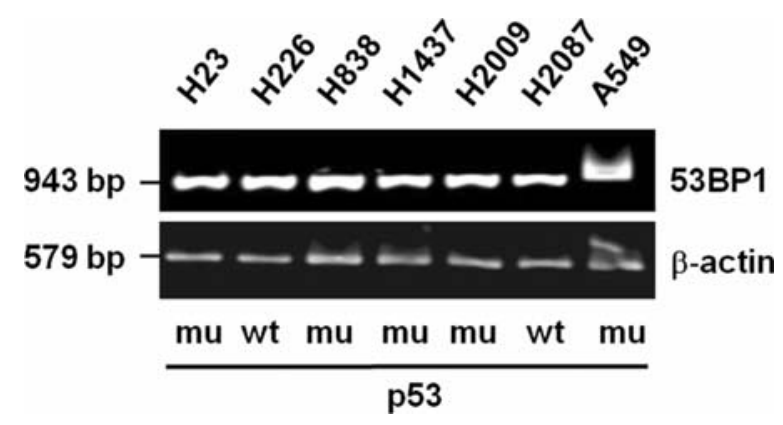

Figure 1. Expression of 53BP1 mRNA detected by RT-PCR in lung adenocarcinoma cell lines. Expression of $\beta$-actin was used as a monitoring standard for the relative expression ratio of 53BP1 mRNA. wt, wild-type p53; mu, mutant p53.

variables exceeded two categories. Survival curves were plotted using the Kaplan-Meier estimator (18). Statistical difference in survival between different groups was compared by the log-rank test (between $53 \mathrm{BP} 1^{+}$and 53BP1- groups) (19). Analysis of covariance and the Mantel-Haenszel $\chi^{2}$ procedure were used to evaluate the difference of cytotoxicity curves among the various groups. Statistical analysis was performed using GraphPad Prism5 statistical software (San Diego, CA). Statistical significance was set at p-value $<0.05$.

\section{Results}

Expression of 53BP1 in LADC cells determined by RT-PCR. Expression of 53BP1 mRNA was determined by RT-PCR in seven lung cancer cell lines, and 53BP1 mRNA was detected in all the cancer cell lines (Fig. 1). Following sequence analysis (by Mission Biotech, Taipei, Taiwan; www.missionbio.com.tw), nucleotide sequence of cDNA fragments from the seven lung cancer cell lines matched that of 53BP1: Homo sapiens p53 tumor suppressor-binding protein 1, Homo sapiens, AF078776.1, mRNA, identities = 936/943 (99.26\%). Expression of 53BP1 mRNA, however, was not correlated with that of either wild-type or mutant p53 gene in these cells (Fig. 1).

Characterization of monoclonal antibodies to 53BP1 and expression of $53 B P 1$ in $L A D C$ cell lines. Specificity of monoclonal antibodies was determined by immunoblotting of the H226 and MCF-7 cell lysate. The predicted molecular mass of 53BP1 is $220-\mathrm{kDa}$. However, our antibodies recognized an extra $250-\mathrm{kDa}$ protein band, which was about $30-\mathrm{kDa}$ larger than the anticipated 53BP1, and we labeled this protein band as $53 \mathrm{BP}^{*}$ (Fig. 2A). The unique $250-\mathrm{kDa}$ protein was precipitated by monoclonal antibodies and protein $\mathrm{G}$ sepharose $\mathrm{s}^{\mathrm{TM}}$ (Fig. 2B) and characterized by MALDI-TOF. The peptide mass fingerprints of the $250-\mathrm{kDa}$ protein matched that of 53BP1:UniProtKB/Swiss-Prot:Q12888.1, tumor suppressor p53-binding protein 1 (53BP1, p220), Homo sapiens (Human). The matched peptides covered 49\% (966/1972 amino acid residues) of the protein. No ubiquitin or sumo residue was detected. In H1437, the $250-\mathrm{kDa} 53 \mathrm{BP} 1^{*}$ band was also detected (Fig. 2C). However, the $250-\mathrm{kDa} 53 \mathrm{BP} 1^{*}$ signal was not recognized in the lung cancer specimens (Fig. 2D). 
A

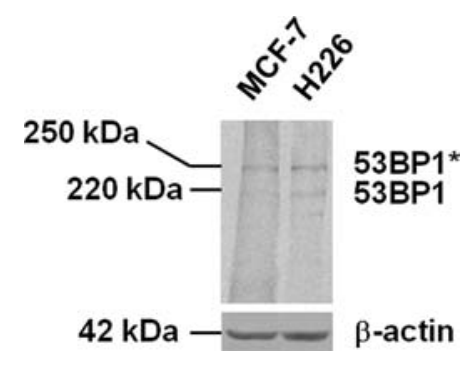

C

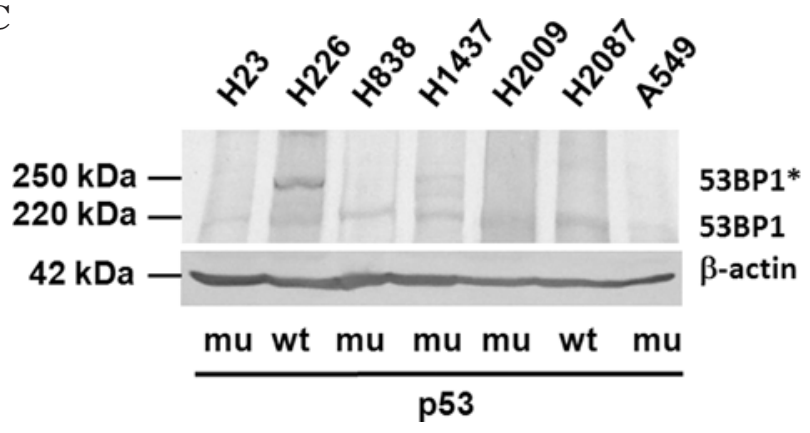

$\mathbf{E}$

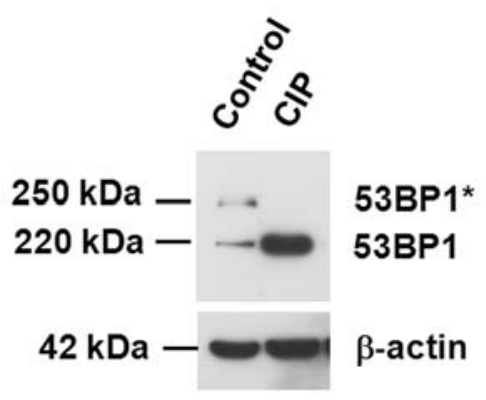

The higher molecular weights in MCF-7, H226 and h1437 suggested that the $250-\mathrm{kDa} 53 \mathrm{BP} 1^{*}$ was modified posttranslationally. Treatment of cell lysate with calf intestinal alkaline phosphatase (CIP) before immunoblotting showed a reduction of $250-\mathrm{kDa}$ protein, and an increase of $220-\mathrm{kDa}$ protein (Fig. 2E), indicating that the $250-\mathrm{kDa} 53 \mathrm{BP} 1^{*}$ could be a phosphorylated form (20). We also probed 53BP1 specific antibody-precipitated proteins with antibodies to ubiquitin or to sumoyl residues. The result was negative (data not shown).

Elevated expression of 220- and 250-kDa 53BP1 increases cisplatin resistance. Because nicotine, a major ingredient in cigarette, induces DNA damage (21), we tested the effect of nicotine on expression of 53BP1. Addition of nicotine to $\mathrm{H} 23$ cells increased levels of both 220-kDa 53BP1 and 250-kDa 53BP1* (Fig. 3A) as well as cell resistance to cisplatin (Fig. 3B). Using siRNA to knock down 53BP1 (53BP $1^{\mathrm{kd}}$ ) expression in H1437 cells (Fig. 3C), however, reduced cisplatin resistance (Fig. 3D). These results supported our anticipation that 53BP1 expression could be associated with cisplatin resistance of the lung cancer cells.
B

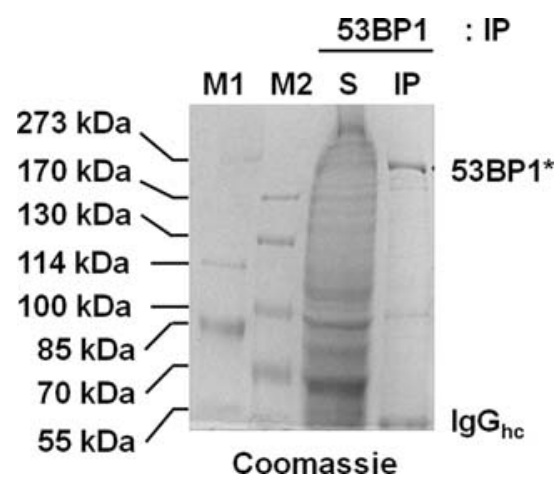

D

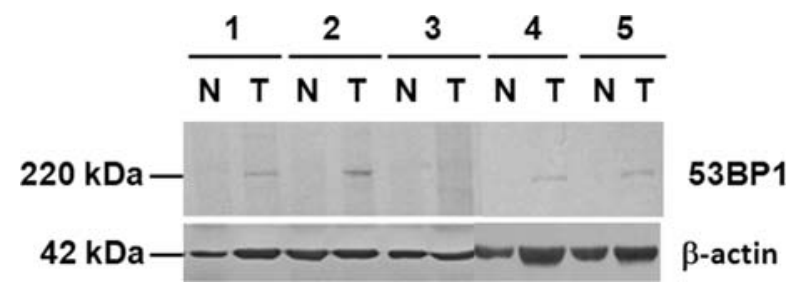

Figure 2. Characterization of monoclonal antibodies to 53BP1 by (A) using immunoblotting; a 220-kDa 53BP1 and a 250-kDa 53BP1* were detected in MCF-7 and H226 cells. (B) The unique $250-\mathrm{kDa}$ protein was precipitated by monoclonal antibodies and protein $\mathrm{G}$ sepharose. The protein band corresponding to 53BP1 was excised and characterized by MALDI-TOF. The peptide mass fingerprints of the $250-\mathrm{kDa}$ protein matched that of 53BP1: UniProtKB/Swiss-Prot:Q12888.1, tumor suppressor p53-binding protein 1 (53BP1, p220) [Homo sapiens (Human)]. (C) 53BP1 expression, detected in all of the lung adenocarcinoma cell lines, was independent of the status of p53. wt, wild-type p53; mu, mutant p53; (D) Only 220-kDa 53BP1 was detected in four of five lung adenocarcinoma specimens. (E) H1437 Cell lysate was treated with calf intestinal alkaline phosphatase (CIP) before immunoblotting reduced the $250-\mathrm{kDa}$ protein band, but increased the $220-\mathrm{kDa}$ protein band.

Expression of 53BPI in $L A D C$. Using immunohistochemistry, 53BP1 was detected in $166(75.8 \%)$ of LADC pathological samples (Fig. 4A-C). Among 148 of the 166 (89.1\%) pathological specimens the 53BP1 could be identified in the nuclei of cancer cells (Fig. 4A and B). 53BP1 expression was also detected in $84.9 \%$ (79/93) of metastatic lymph nodes (data not shown). Statistical analysis showed that expression of 53BP1 correlated with tumor stage, cigarette smoking, and lymphovascular involvement (Table I), suggesting that 53BP1 expression was associated with tumor cell growth, and possibly metastasis of LADC cells. Moreover, among the 166 patients who had high levels of 53BP1, 98 (59.0\%) had tumor recurrence during follow-up examination. Among the 53 patients who had low levels of 53BP1, 15 had tumor recurrence (28.3\%). All 103 patients who had recurrence developed tumors within 24 months after operation. The risk of recurrence for patients with high levels of 53BP1 was 3.651-fold higher than that for patients with low levels of 53BP1 $(\mathrm{p}<0.01)$. Survival of patients with low 53BP1 levels was significantly better than that of patients with high 53BP1 levels (Fig. 4E). The hazard ratio between these two groups was 1.987, and the difference in cumulative survival was significant $(\mathrm{p}=0.0016)$. 
A

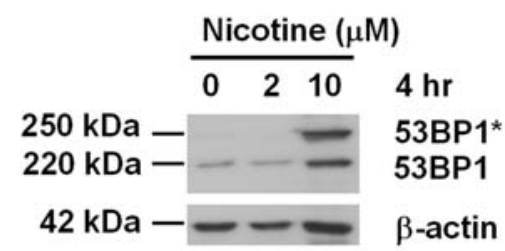

B

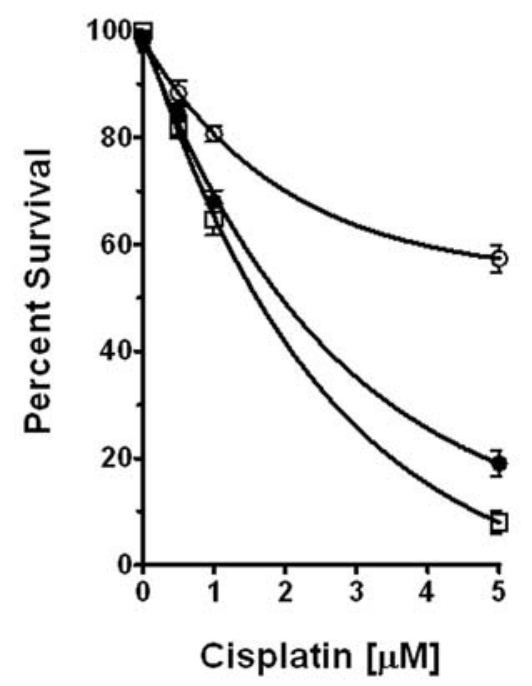

C

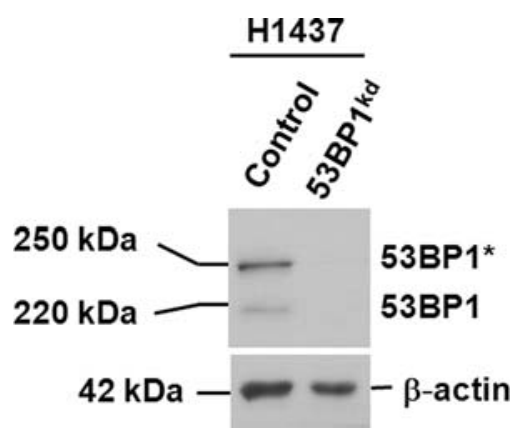

D

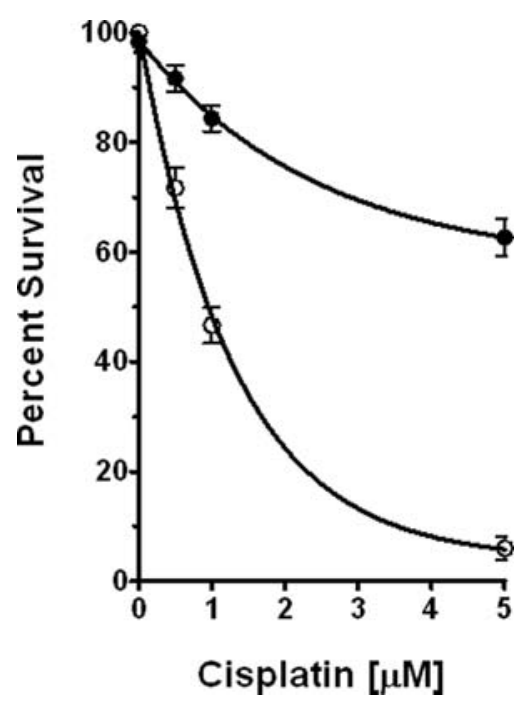

Figure 3. Effect of 53BP1 expression on cisplatin cytotoxicity. (A) Addition of nicotine at $37^{\circ} \mathrm{C}$ for $4 \mathrm{~h}$ induced 53BP1 expression in $\mathrm{H} 23$ cells. (B) Elevated 53BP1 expression significantly increased cisplatin sensitivity. $\square$, control $\mathrm{H} 23$ cells; $\bullet, \mathrm{H} 23$ cells treated with $2 \mu \mathrm{M}$ of nicotine prior to cisplatin treatment; $\circ, \mathrm{H} 23$ cells treated with $10 \mu \mathrm{M}$ of nicotine prior to cisplatin treatment $(\mathrm{p}<0.01)$; (C) Knockdown of 53BP1 (53BP1 $1^{\mathrm{kd}}$ )-specific expression by siRNA reduced 53BP1 expression in H1437 cells. (D) Compared to the control $\mathrm{H} 1437$ cells $(\bullet), 53 \mathrm{BP} 1^{\mathrm{kd}}$ cells (o) are significantly more sensitive to cisplatin $(\mathrm{p}<0.01)$.

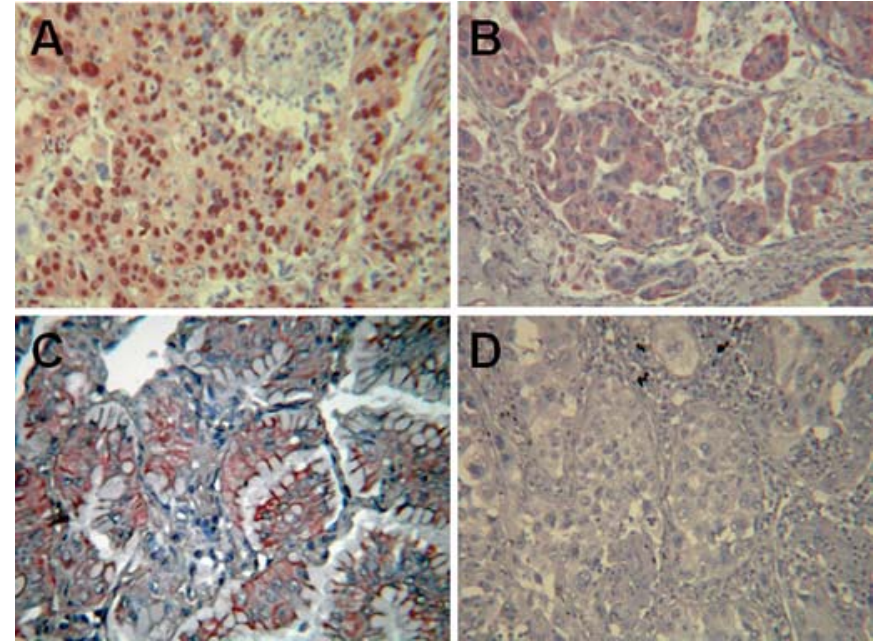

$\mathbf{E}$

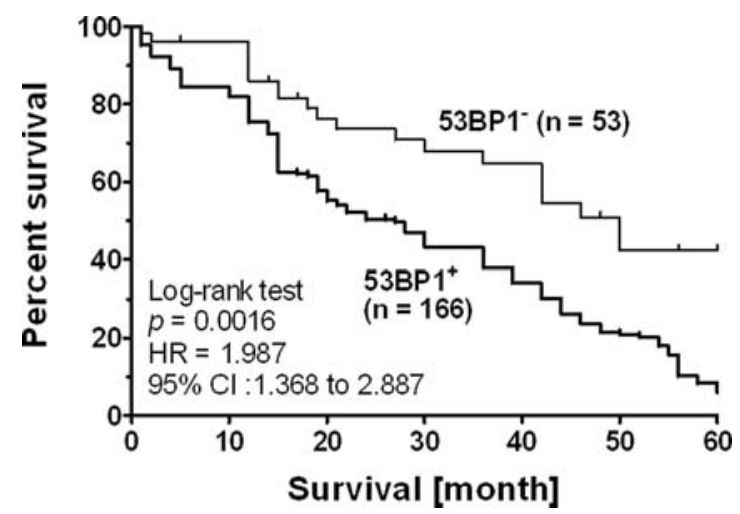

Figure 4. Correlation between 53BP1 expression and survival in patients with LADC. Representative examples of 53BP1 expression in pathological specimens as detected by immunohistochemical staining (as crimson precipitates). (A) 53BP1 was detected only in the nuclei of LADC cells, and (B) both in the nuclei and cytoplasm of LADC cells. (C) 53BP1 was detected only in the cytoplasm of mucinous LADC cells. (D) 53BP1-negative LADC cells; (E) Comparison of Kaplan-Meier product limit estimates of survival analysis in patients with LADC. Patients were divided into two groups based on expression of 53BP1. Survival difference between the two groups was compared by a log-rank test; $\mathrm{p}=0.0016$.

Multivariate analysis also showed a significant statistical difference in 53BP1 expression between the two groups $(\mathrm{p}=0.0276)$.

\section{Discussion}

The results showed that antibodies generated in our study recognized the 53BP1. In LADC sections 53BP1 was frequently detected in the nuclei of cancer cells. Expression of 53BP1 correlated with the advanced tumor stage, lymphovascular invasion and patients' cigarette smoking habits, suggesting that 53BP1 expression was associated with cigarette smoking and disease progression of LADC.

As shown by immunoblotting, in addition to the $220-\mathrm{kDA}$ protein which was frequently detected in the pathological specimens, a 250-kDa 53BP1* was detected in H226, H1437 and MCF-7 cells. Intensity of the $250-\mathrm{kDa}$ protein reduced to $220-\mathrm{kDa}$ following CIP treatment, supporting the fact that 53BP1 was phosphorylated (20). Since increase of 53BP1 
Table I. Correlation of 53BP1 expression with clinicopathological parameters of LADC.

\begin{tabular}{|c|c|c|c|c|}
\hline \multirow[b]{2}{*}{ Parameter } & \multicolumn{2}{|c|}{ Expression of 53BP1 } & \multicolumn{2}{|c|}{ P-value } \\
\hline & High $(n=166)$ & Low $(n=53)$ & Univariate & Multivariate \\
\hline \multicolumn{5}{|l|}{ Gender } \\
\hline Male $(n=153)$ & 119 & 34 & $0.298^{\mathrm{a}}$ & 0.508 \\
\hline Female $(n=66)$ & 47 & 19 & & \\
\hline \multicolumn{5}{|l|}{ Cigarette smoking ${ }^{\mathrm{b}}$} \\
\hline Smoker $(n=149)$ & 134 & 15 & $<0.001^{\mathrm{a}}$ & 0.026 \\
\hline Non-smoker $(\mathrm{n}=70)$ & 32 & 38 & & \\
\hline \multicolumn{5}{|l|}{ Stage } \\
\hline$I(n=76)$ & 45 & 31 & $<0.001^{\mathrm{a}}$ & 0.012 \\
\hline II (n=81) & 67 & 14 & & \\
\hline III $(n=62)$ & 54 & 8 & & \\
\hline \multicolumn{5}{|l|}{ Cell differentiation } \\
\hline Well $(n=52)$ & 38 & 14 & $0.435^{\mathrm{a}}$ & 0.891 \\
\hline Moderate $(n=102)$ & 75 & 27 & & \\
\hline Poor $(n=65)$ & 53 & 12 & & \\
\hline \multicolumn{5}{|c|}{ Lymphovascular invasion } \\
\hline Positive $(n=93)$ & 79 & 14 & $0.007^{\mathrm{a}}$ & 0.037 \\
\hline Negative $(n=126)$ & 87 & 39 & & \\
\hline
\end{tabular}

${ }^{\text {aTwo-sided }}$ p-value determined by $\chi^{2}$ test. ${ }^{b}$ In this study, smoker is defined as a person who is constantly exposed to cigarette smoking, including non-smoker patients living in the same household where the spouse or a relative smoked more than one pack per week $(\sim 50$ packs/year).

expression facilitates DNA repair, it is thus interesting to note that addition of nicotine elevates 53BP1 expression and increases cisplatin resistance (21). Silencing of 53BP1 by siRNA, on the other hand, reduces cisplatin resistance. These data suggest that expression of 53BP1 is important for drug resistance of LADC. Patients who have higher 53BP1 levels are more resistant to cisplatin-based chemotherapy and have worse prognosis. Patients who have lower levels of 53BP1, on the other hand, are more sensitive to cisplatin-based chemotherapy and have better prognosis. By showing that cancer cells with dominant-negative 53BP1 phenotype have higher frequency of camptothecin-induced cell death, results by Yoo et al support our observations and indicate that 53BP1 expression is associated with drug resistance (12).

Using immunohistochemistry Gorgoulis et al detected 53BP1 expression in the non-small cell lung cancer (NSCLC) (22). Detection rate was 93.2\% (69/74), and 53BP1 expression was not dependent on the status of p53, wild-type or mutant (22). Moreover, 53BP1 expression in NSCLC cells correlated with cell proliferation, as determined by KI67 expression, as well as protein and protein phosphorylation levels of CHK2, a DNA damage-related signaling kinase $(22,23)$. Interestingly, CHK2 was not phosphorylated in the absence of 53BP1 $(22,24)$, and CHK2 expression was essential for cisplatin resistance (25).
DNA repair, in particular nucleotide excision repair (NER), has long been associated with drug resistance (26-28). An elegant in vitro study by Niedernhofer et al showed that excision repair cross-complementation group 1 (ERCC1) was required for repairing cisplatin-induced DNA damage, confirming that DNA repair was indeed involved in drug resistance (29). Clinically, Olaussen et al found that NSCLC patients with ERCC1-negative tumors responded better to cisplatin-based adjuvant chemotherapy and had better prognosis than those with ERCC1-positive tumors, supporting the facts that ERCC1 was associated with increased drug resistance (30). These results corresponded well with those reported by $\mathrm{Yu}$ et al that both ERCC1 and CHK2 were essential for cisplatin resistance (25). Xeroderma pigmentosum complementation group (XP) $\mathrm{C}$ is important for NER as well. In association with human homolog of yeast $\operatorname{Rad} 23$ protein $B$ (hHR23B), XPC binds DNA damage sites. XPC-hHR23B complex then recruits XPA, RNA polymerase II basal transcription factor b (TFIIH), transcription factor B5 (TFB5) and human replication protein A (RPA) to initiate DNA repair $(31,32)$. 53BP1 also binds RPA, and it is required for the phosphorylation of RPA2 and CHK2 $(12,22,24)$. Interestingly, studies of the DNA damage mediators' functions in ATM activation indicate that 53BP1 not only acts as a mediator for relaying DNA damage signals, but also as a modulator, 
which directly interacts with the Mre11/Rad50/NBS1 (MRN) complex and promotes kinase activity of ATM (33). The MRN complexes are essential for the repair of DNA doublestrand breaks, e.g., homologous recombination, non-homologous end-joining (NHEJ) and preservation of telomeres (34-36).

It is worth noting that cigarette smoke introduces both intrastranded and interstranded DNA damage as well as shortening of telomeres (37-39). It is possible that cigarette smoke concurrently increases expression of p53 and DNA repair-related proteins, including 53BP1, XPC and ERCC1. However, for such pathophysiological responses, other explanations are feasible, for instance, cigarette smoke increases expression of hepatocyte growth factor (HGF) in type II pneumocytes and lung cancer cells, which not only elevates metastatic potential, but also down-regulates apoptosisinducing factor (AIF) expression and reduces cisplatin toxicity in LADC cells $(2,3)$.

In conclusion, immunoblotting and immunohistochemistry revealed abundant expression of 53BP1 in lung adenocarcinoma cells. Pathological results suggest that 53BP1 expression is associated with tumor stage, lymphovascular invasion and cigarette smoking habits of the patients, which reflects the increased tumor cell growth, metastasis and poor prognosis of patients with LADC. In vitro, nicotine increased 53BP1 expression and cisplatin resistance. Silencing of 53BP1 expression, however, reduced cisplatin resistance. These data suggest that 53BP1 plays an important role in drug resistance of lung adenocarcinoma cells.

\section{Acknowledgements}

RNAi for silencing 53BP1 gene expression was obtained from the National RNAi Core Facility in the Institute of Molecular Biology/Genomic Research Center, Academia Sinica, Taipei, Taiwan, supported by the National Research Program for Genomic Medicine Grants of NSC (NSC 97-3112-B-001-016). This study was supported, in part, by the Comprehensive Academic Promotion Projects, National Chung Hsing University, Taichung, Taiwan (NCHU 985005 to K.C.C.).

\section{References}

1. Moran CA and Suster S: Tumors of the lung and pleura. In: Diagnostic Histopathology of Tumors. Fletcher CDM (ed). Churchill Livingstone, London, pp171-208, 2000.

2. Chen JT, Lin TS, Chow KC, et al: Cigarette smoking induces overexpression of HGF in type II pneumocytes and lung cancer cells. Am J Respir Cell Mol Biol 34: 264-273, 2006.

3. Chen JT, Huang CY, Chiang YY, et al: HGF increases cisplatin resistance via down-regulation of AIF in lung cancer cells. Am J Respir Cell Mol Biol 38: 559-565, 2008.

4. Olive PL and Durand RE: Drug and radiation resistance in spheroids: cell contact and kinetics. Cancer Metastasis Rev 13: $121-138,1994$

5. Lu X and Lane DP: Differential induction of transcriptionally active p53 following UV or ionizing radiation: defects in chromosome instability syndromes? Cell 75: 765-778, 1993.

6. Bartek $J$ and Lukas $J$ : Mammalian $\mathrm{G}_{1}$ and $\mathrm{S}$ phase checkpoints in response to DNA damage. Curr Opin Cell Biol 13: 738-747, 2001

7. Wu X, Roth JA, Zhao H, et al: Cell cycle checkpoints, DNA damage/repair and lung cancer risk. Cancer Res 65: 349-357, 2005 .
8. Liebermann DA, Hoffman B and Vesely D: p53 induced growth arrest versus apoptosis and its modulation by survival cytokines. Cell Cycle 6: 166-170, 2007.

9. Steels E, Paesmans M, Berghmans T, et al: Role of p53 as a prognostic factor for survival in lung cancer: a systematic review of the literature with a meta-analysis. Eur Respir J 18: 705-719, 2001.

10. Iwabuchi K, Bartel PL, Li B, Marraccino R and Fields S: Two cellular proteins that bind to wild-type but not mutant p53. Proc Natl Acad Sci USA 91: 6098-6102, 1994.

11. Iwabuchi K, Basu BP, Kysela B, et al: Potential role for 53BP1 in DNA end-joining repair through direct interaction with DNA. J Biol Chem 278: 36487-36495, 2003.

12. Yoo E, Kim BU, Lee SY, Cho CH, Chung JH and Lee $\mathrm{CH}$ : $53 \mathrm{BP} 1$ is associated with replication protein $\mathrm{A}$ and is required for RPA2 hyperphosphorylation following DNA damage. Oncogene 24: 5423-5430, 2005.

13. DiTullio RA Jr, Mochan TA, Venere M, et al: 53BP1 functions in an ATM-dependent checkpoint pathway that is constitutively activated in human cancer. Nat Cell Biol 4: 998-1002, 2002.

14. Zgheib O, Huyen Y, DiTullio RA Jr, et al: ATM signaling and 53BP1. Radiother Oncol 76: 119-122, 2005.

15. Mountain CF: Revisions in the International System for Staging Lung Cancer. Chest 111: 1710-1717, 1997.

16. Chow KC and Ross WE: Topoisomerase-specific drug sensitivity in relation to cell cycle progression. Mol Cell Biol 7: 3119-3123, 1987

17. Remmele W and Schicketanz KH: Immunohistochemical determination of estrogen and progesterone receptor content in human breast cancer. Computer-assisted image analysis (QIC score) vs. subjective grading (IRS). Pathol Res Pract 189: 862-866, 1993.

18. Kaplan EL and Meier P: Non-parametric estimation from incomplete observations. J Am Stat Assoc 53: 457-481, 1958.

19. Mantel N: Evaluation of survival data and two new rank order statistics arising in its consideration. Cancer Chemother Rep 50: 163-170, 1966.

20. Kang Y, Lee JH, Hoan NN, Sohn HM, Chang IY and You HJ: Protein phosphatase 5 regulates the function of 53BP1 after neocarzinostatin-induced DNA damage. J Biol Chem 284: 9845-9853, 2009.

21. Yoshida H, Sakagami H, Yamanaka Y, et al: Induction of DNA fragmentation by nicotine in human myelogenous leukemic cell lines. Anticancer Res 18: 2507-2511, 1998.

22. Gorgoulis VG, Vassiliou LV, Karakaidos P, et al: Activation of the DNA damage checkpoint and genomic instability in human precancerous lesions. Nature 434: 907-913, 2005.

23. Bartek J, Falck J and Lukas J: CHK2 kinase - a busy messenger. Nat Rev Mol Cell Biol 2: 877-886, 2001.

24. Matsuoka S, Rotman G, Ogawa A, Shiloh Y, Tamai K and Elledge SJ: Ataxia telangiectasia-mutated phosphorylates Chk2 in vivo and in vitro. Proc Natl Acad Sci USA 97: 10389-10394, 2000.

25. Yu JJ, Liang X, Yan QW, et al: CHK2 and ERCC1 in the DNA adduct repair pathway that mediates acquired cisplatin resistance. In: Platinum and Other Heavy Metal Compounds in Cancer Chemotherapy. Bonetti A, Leone R, Muggia FM and Howell SB (eds). Humana Press, New York, pp189-194, 2009.

26. Nuciforo PG, Luise C, Capra M, Pelosi G and D'Adda di Fagagna F: Complex engagement of DNA damage response pathways in human cancer and in lung tumor progression. Carcinogenesis 28: 2082-2088, 2007.

27. Rosell R, Mendez P, Isla D and Taron M: Platinum resistance related to a functional NER pathway. J Thorac Oncol 2: 1063-1066, 2007.

28. Vaisman A, Varchenko M, Umar A, et al: The role of hMLH1, hMSH3 and hMSH6 defects in cisplatin and oxaliplatin resistance: correlation with replicative bypass of platinum-DNA adducts. Cancer Res 58: 3579-3585, 1998.

29. Niedernhofer LJ, Odijk H, Budzowska M, et al: The structurespecific endonuclease Ercc1-Xpf is required to resolve DNA interstrand cross-link-induced double-strand breaks. Mol Cell Biol 24: 5776-5787, 2004

30. Olaussen, KA, Dunant A, Fouret P, et al: DNA repair by ERCC1 in non-small cell lung cancer and cisplatin-based adjuvant chemotherapy. N Engl J Med 355: 983-991, 2006.

31. De Laat WL, Jaspers NG and Hoeijmakers JH: Molecular mechanism of nucleotide excision repair. Genes Dev 13: C768-C785, 1999.

32. Wood RD, Mitchell M, Sgouros J and Lindahl T: Human DNA repair genes. Science 291: 1284-1289, 2001. 
33. Lee JH, Goodarzi AA, Jeggo PA and Paull TT: 53BP1 promotes ATM activity through direct interactions with the MRN complex. EMBO J 29: 574-585, 2009.

34. D'Amours D and Jackson SP: The Mre11 complex: at the crossroads of DNA repair and checkpoint signalling. Nat Rev Mol Cell Biol 3: 317-327, 2002

35. Deng Y, Guo X, Ferguson DO and Chang S: Multiple roles for MRE11 at uncapped telomeres. Nature 460: 914-918, 2009.

36. Dinkelmann M, Spehalski E, Stoneham T, et al: Multiple functions of MRN in endjoining pathways during isotype class switching. Nat Struct Mol Biol 16: 808-813, 2009.
37. Matsuda T, Kawanishi M, Yagi T, Matsui S and Takebe H: Specific tandem GG to TT base substitutions induced by acetaldehyde are due to intra-strand crosslinks between adjacent guanine bases. Nucleic Acids Res 26: 1769-1774, 1998.

38. Lao Y and Hecht SS: Synthesis and properties of an acetaldehydederived oligonucleotide interstrand cross-link. Chem Res Toxicol 18: 711-721, 2005

39. Jang JS, Choi YY, Lee WK, et al: Telomere length and the risk of lung cancer. Cancer Sci 99: 1385-1389, 2008. 